\title{
UN REPASO A TRAVÉS DE LOS CONCEPTOS DE EPIGRAFÍA E INSCRIPCIÓN
}

\author{
REVIEWING THE CONCEPTS \\ "EPIGRAPHY AND INSCRIPTION"
}

NATALIA RODRÍGUEZ SUÁREZ

Universidad de León

\begin{abstract}
Resumen: El artículo hace un repaso por las distintas definiciones que se han dado a los conceptos de epigrafía e inscripción, hasta llegar a la definición actual de inscripción; entendida como escrito de carácter publicitario, universal y perdurable: A partir de ciertas reflexiones esta definición queda matizada, señalando que la universalidad y la perdurabilidad son valores relativos, circunscritos y aplicables al uso que el autor pretende darle a la inscripción.
\end{abstract}

Palabras clave: Epigrafía, Inscripción, Medieval, Concepto, Definición.

\begin{abstract}
The article maker an overview of the different definitions given to the concept of epigraphy and inscription before the current definition of inscription, defined as a document with advertising, universal and enduring nature: After certain reflections this definition must be clarified, highlighting that the universality and durability are relative, limited and applicable to intended of inscription by the author.
\end{abstract}

Keywords: Epigrapy, Inscription, Medieval, Concept, Definition.

Los conceptos de epigrafía e inscripción han sido ampliamente definidos y sin embargo, la juventud de la Epigrafía medieval, hace que las definiciones aún estén abiertas, lo que nos permite hacer algunas matizaciones.

Las primeras definiciones de Epigrafía acudían al sentido etimológico de la misma, cuya traducción desde el griego viene a ser "escribir sobre”. Esta definición resulta del todo imprecisa pues, toda escritura estaría fijada siempre sobre un soporte. También resulta demasiado genérica la explicación que planteaba René Cagnat en 1914 "la science des inscriptions”", sin llegar a precisar que es inscripción. Por ello, pronto se buscaron nuevas matizaciones al concepto.

\footnotetext{
${ }^{1}$ R. CAGNAT, Cours d’Épigraphie Latine, $3^{\mathrm{a} e d, ~ P a r i ́ s, ~ 1914, ~ p . ~ X I I I . ~}$
} 
Así el profesor Batelli explicaba que "delle scriture su pietra, su bronzo, su terracotta si occupa l'epigrafia" ${ }^{2}$. Se estaba definiendo esta ciencia en función del soporte, que para este caso únicamente eran materias duras. El profesor Batelli intentaba además precisar los límites entre la Epigrafía y la Paleografía ${ }^{3}$. Su definición fue aceptada por muchos, llegándose a implantar el concepto de Epigrafía entendido como la ciencia que tenía por objeto el estudio de las escrituras sobre materia dura ${ }^{4}$.

Jean Mallon ya advirtió esto y se dio cuenta, además, de que el intento de separación entre la Epigrafía y la Paleografía era innecesario, pues en las inscripciones se podían analizar los textos, esto es: los caracteres internos, como se venía haciendo; pero también eran y debían ser susceptibles de estudiarse sus caracteres externos, es decir sus grafías, lo que ponía estos estudios en paralelo directo a la Paleografía ${ }^{5}$. Se abría paso, entonces, un método de estudio epigráfico más global, que tímidamente ya habían iniciado algunos años antes los profesores Hübner, Lasteyrie, Deschamps, Diehl o Vives ${ }^{6}$. Estas enseñanzas fueron pronto recogidas por don Joaquín María de Navascués y de Juan, que aplica este método de trabajo a las inscripciones de Mérida, como explicó en su discurso de ingreso en la Real Academia de la Historia ${ }^{7}$. De este modo, Mallon y Navascués abrieron nuevos horizontes al estudio epigráfico.

Volviendo al concepto de Epigrafía Jean Mallón sugirió que junto con las materias duras existían textos, con características similares, en soportes cuyo grado de dureza era menor y que, por ello, la Epigrafía era una ciencia mal definida “les "inscriptions", ce sont les monuments qui trouvent traditionnellement leur place dans le Corpus tel qu'il a été conçu au dix-neuvième siècle, et qui forment

${ }^{2}$ G. BATELLI, Lezioni di Paleografia, Ciudad del Vaticano, $3^{\mathrm{a}}$ ed., 1949, p. 3.

${ }^{3}$ J. MALLON. Paléographie romaine, Madrid, 1952, p. 55.

${ }^{4}$ R. BLOCH, L’Épigraphie latine, París, 1952, p. 5. I. CALABI, Epigrafía latina, Milán, 1968, p. 13.

${ }^{5}$ J. MALLON, Paléographie, pp. 55-73.

${ }^{6}$ E. HÚBNER, Inscriptiones Hispaniea Christianae, Berlín, 1871. El especial interés que este erudito concedía a la paleografía epigráfica se ve reflejado en E. HÜBNER, Exempla scripturae epigraphicae latinae a Caesaris dictatoris morte ad aetatem Iustiniani, Berlín, 1885. R. DE LASTEYRIE, Études sur la sculture française au Moyen Âge, Paris, 1902, E. DIEHL, Inscriptiones latinae Christianae Veteres, Berlín, 1925, P. DESCHAMPS, Étude sur la paléographie des inscriptions lapidaires de la fin de l'époque mérovingienne aux dernières années du XII ${ }^{e}$ siècle, Paris, 1929, pp. 5-86, J. VIVES, Inscripciones cristianas de la España romana y visigoda, Barcelona, 1969.

${ }^{7}$ J. M ${ }^{\text {a }}$. DE NAVASCUES y DE JUAN, El concepto de Epigrafía. Consideraciones sobre la necesidad de su ampliación. Discursos leídos ante la Real Academia de la Historia por los señores D. Joaquín $M^{a}$. de Navascués y de Juan y D. Manuel Gómez-Moreno y Martínez en la recepción pública del primero el día 18 de enero de 1953, Madrid, 1953, p. 27. 


\section{NATALIA RODRÍGUEZ SUÁREZ \\ UN REPASO A TRAVÉS DE LOS CONCEPTOS DE EPIGRAFÍA E INSCRIPCIÓN}

ainsi l'objet d'une science mal définie, dont les frontières avec d'autres sciences, surtout avec la paléographie, sont très arbitraires : ...Il s'agit d'une masse innombrable et hétéroclite de monuments : inscriptions sur pierre, sur cire, sur métaux, sur terre cuite et sur parois, faites au moyen du ciseau, de la pointe sèche et du pinceau, qui, plus ou moins denses selon les régions et les époques, recouvrent pourtant toute l'étendue du monde romain et jalonnent toute la longueur de l'historie romaine”" . El propio Susini citando a Mallón dice que "per lo più si tratta di insigne, in materialo diversi, non sempre le pietre o il bronzo o la terracotta ma anche la plastica, il vetrom ola tela”' ${ }^{9}$. Aún más, matiza la definición aludiendo no sólo a materias duras sino a "semi-durables" “iscrizione, che alude ya a materiales semidurables ${ }^{10}$.

La cuestión sobre el concepto de Epigrafía y el método de trabajo de los propios epigrafistas era un tema que preocupaba al iniciarse la década de los cincuenta $^{11}$. Los planteamientos sobre el concepto de Epigrafía que se estaban empleando suponían un doble problema, por un lado, al ajustar la definición de Epigrafía a la dureza del soporte, ciertos objetos que debían ser inscripciones quedaban fuera, y otros que no lo eran, podían entenderse como tales, aplicando esta definición ${ }^{12}$. Por otro lado, el intento de contraposición entre Paleografía y Epigrafía resultaba absurdo, como ya indicó Mallon en su momento, abogando incluso por la fusión de ambas disciplinas ${ }^{13}$. La necesidad de revisión del concepto quedaba patente el segundo Congreso Internacional de Epigrafía Griega y Latina, que tuvo lugar en París entre los días 15 y 19 de abril de 1952. El discurso inaugural ponía en evidencia la cuestión con la pregunta que Louis Robert dejaba en el aire ¿cuál es la tarea del epigrafista? "Nous sommes réunis ici entre épigraphistes. Mais qui sommes-nous?"14.

Esta cuestión estaba en el pensamiento de algunos epigrafistas y así vemos cómo Manuel Gómez-Moreno, en su respuesta al discurso de ingreso a la Real

${ }^{8}$ J. MALLON. Paleographie. p. 55.

${ }^{9}$ G. SUSINI, Epigrafia romana, Roma, 1982, p. 13.

${ }^{10}$ G. SUSINI, Epigrafia romana..., p. 13.

11 Junto a Diehl, Vives, Mallon, hemos de citar a J. GORDON, Contributions to the paleography of latin inscriptions, Berkley y Los Ángeles, 1957. Otros como R. BLOCH, L'Épigraphie... seguían ligados al concepto tradicional.

12 Cf. la reflexión que ha este respecto hace M. J. BARROCA, Epigrafía medieval portuguesa (862-1422), vol. I, Oporto, 2000, pp. 12-33.

13 J. MALLON, “Qu'est-ce que l'Épigraphie”: Epigraphie Hispanique. Problèmes de méthode et d'édition, Paris, 1984, pp. 157-159 y el debate que se generó, pp. 160-163.

${ }^{14}$ L. ROBERT, “Communication inaugurale”, Actes du Deuxiéme congrès international d'épigraphie grecque et latine Paris 1952, Paris, 1953, p. 1. 
Academia de la Historia de don Joaquín María de Navascués y de Juan, el 18 de enero de 1953, definía el epígrafe como: “composición literaria para conmemorar un hecho en condiciones monumentales. Publicidad, solemnidad y perduración la caracterizan, y estos son los requisitos exigibles para entrar en el noble acervo de la Epigrafía"15.

El profesor Gómez-Moreno, ofrecía una definición de Epigrafía que rompía definitivamente con la dureza del soporte, y abría un nuevo camino, al poner el acento en la funcionalidad última del mensaje que presenta. Poco a poco fue calando la idea de que había que desligar la definición de Epigrafía del soporte en el que se presentaba el objeto de estudio.

Los planteamientos expuestos, a partir de los años cincuenta, por todos estos especialistas fueron recuperados y difundidos por el profesor Favreau, que en 1969 ya ofrecía la definición de Epigrafía que se ha consolidado actualmente. "On pourrait donc proponer comme nouvelle définition de l'épigraphie : science de ce qui est écrit, en général sur une matière résistante, en vue d'une publicité universelle et durable" ${ }^{16}$ y advertía que incluía la referencia al material por la ligazón con la definición tradicional. "La notion de matière pourrait être maintenue afin d'assurer une liaison avec la définition traditionnelle, mais on doit bien admettre que le support matériel de l'inscription est, en tant que tel, indifférent"17.

Otros le siguieron, por ejemplo Stiennon quien señalaba, en 1973, que "Plusieurs érudits ont déjà relevé le caractère arbitraire de cette distinction: où commence le matériau dur et où finit le support souple?" 18.

Diez años más tarde el profesor Favreau seguía insistiendo en la misma definición; pero, ya desligado totalmente del soporte. Advertía que la dureza del material no podía servir de base a la definición de Epigrafía "On ne peut pas plus retenir comme fondamentale la notion de matière "dure", "non périssable"19 y acaba definiendo inscripción como "ce qui est écrit sur un monument ou en objet

\footnotetext{
${ }^{15}$ M. GÓMEZ MORENO, El concepto de la Epigrafía. Consideraciones sobre la necesidad de su ampliación, Discursos leídos ante la Real Academia de la Historia por los señores D. Joaquín $M^{a}$. de Navascués y de Juan y D. Manuel Gómez-Moreno y Martínez en la recepción pública del primero, el día 18 de enero de 1953, Madrid, 1953, p. 93. J. DE SANTIAGO FERNÁNDEZ, "La Epigrafía: Evolución conceptual y metodológica”, Documenta \& Instrumenta, n. 1, Madrid, 2004, pp. 203-220 recupera las aportaciones que para el concepto de epigrafía supuso este discurso.

${ }^{16}$ R. FAVREAU, “L'Épigraphie médiévale”, Cahiers de civilisation médiévale, Poitiers, XII Année n. 4 Octobre-Décembre, 1969, p. 395.

${ }^{17}$ R. FAVREAU, “L’Épigraphie médiévale”, p. 395.

18 J. STIENNON, Paleographie du Moyen Âge, Paris, 1973, p. 134.

${ }^{19}$ R. FAVREAU, Les inscriptions médiévales, Turnhout, 1979, p. 13.
} 
donné, en vue d'une publicité universelle et durable»20. Robert Favreau coincide con la definición del profesor Gómez-Moreno, incluyendo eso sí, el concepto de universalidad.

La preocupación por el tema proseguía y fiel reflejo de ello es la encuesta que en el año 81 de publicó en la revista Scrittura e civiltá bajo el título Epigrafia e Paleografia. Inchiesta sui rapporti fra due discipline. En ella se ofrecía a diversos especialistas la oportunidad de reflexionar sobre este asunto ${ }^{21}$.

Existen otros intentos de definir el concepto, por ejemplo, el del profesor Kloos, en el año 1992. Presenta una definición aún muy asociada al intento de separación entre Paleografía y Epigrafía y a la dureza del soporte, ofreciendo algunos ejemplos del mismo, y ligando el concepto de Epigrafía a los escritos que no se asociasen ni a las chancillerías ni a las escuelas notariales "Inschriften sind Beschriftungen verschiedener Materialen - in Stein, Holz, Metall, Leder, Stoff, Email, Glas, Mosaik usw.-, die von Kräften und mit Methoden hergestellt sind, die nicht dem Schreibschul- und Kanzleibetrieb angehören"22.

Sin embargo, hasta hoy la definición más aceptada es la ofrecida por el profesor Favreau, que es seguida por los grandes especialistas en el tema, y así Don Vicente García Lobo define inscripción como "cualquier testimonio escrito en orden a una publicidad universal y perdurable"23. Será este profesor quien nos hable abiertamente de escrituras publicitaria- escritura de notoriedad- que será la que sirve de lazo de unión entre la publicidad epigráfica, la publicidad libraria y la publicidad documental $^{24}$. En la misma linea que el profesor Favreau se desarrolla la tesis de la profesora Lambert: "Per definire correctamente l'epigrafia occorre dunque basarsi sulle funzioni dell'iscrizione, che naturalmente determinano la scelta di un determinato supporto, anche in relazione agli ambiti socio-economici di produzione del testo. Richiamandosi alla sua etimologia, l'epigrafia, nella sua accezione moderna, è la scienza storica che si occupa di ciò che è scritto con l'intenzione di comunicare un messaggio o qualche semplice elemento

\footnotetext{
${ }^{20}$ R. FAVREAU, Les inscriptions médiévales, p. 16.

${ }^{21}$ A. PETRUCCI, Epigrafia, pp. 265-312.

22 R. M. KLOOS, Einführung in die epigraphik des mittelalters und der frühen neuzeit, Auflage, 1992, p. 2.

${ }^{23}$ V. GARCÍA LOBO, Los medios de comunicación social en la Edad Media. La comunicación publicitaria, León, 1991, p. 17.

${ }^{24}$ V. GARCÍA LOBO, “La escritura publicitaria en la Península Ibérica. Siglos X-XIII”, Inschrift und material Inschrift und Buchschrift. Fachtagung für mittelalterliche und neuzeitliche Epigraphik Ingolstadt 1997, München, 1999, pp. 151-190.
} 
informativo ad un pubblico teoricamente il più vario e per la maggior durata di tempo possibile" 25 .

Definiciones que como venimos diciendo son las más aceptadas, a pesar de que ciertos profesionales de la materia abran la puerta a nuevos matices. Es éste el caso del profesor Koch quien señala que la definición ofrecida por el profesor Favreau no ofrece el espectro completo "Dauerhaftigkeit, Publizität- nach Robert Favreau sind "durée und publicité" die vornehmlichen Merkmale einer Inschriftweiters Monumentalität, ja gestaltender Formwille sind zweifellos Kriterien, die insgesamt oder zumindest zum Teil auf zahlreiche Inschriften zutreffen, sie könnenaber letztlich sicherlich nicht das gesamte Spektrum der als Inschrift in Frage kommenden Denkmäler von vornherein charakterisieren” ${ }^{26}$. Además, señala que es preciso plantearse qué ocurre con ciertos rótulos en los códices o en los documentos que presentan muchas concomitancias con la escritura de las inscripciones "Über weite Strecken scheinen in den Inschriften auch Andere Schriftsysteme auf als in den Textschriften der Codices”27. No obstante, la solución a esta inquietud del profesor Koch, la resolvió el profesor Gacía Lobo, con la definición de escritura publicitaria ${ }^{28}$. A partir de entonces, la escritura publicitaria se nos presenta como un modo de escribir, de presentar paleográficamente el texto, un modo de hacer que es el habitual en las inscripciones, pero que también puede utilizarse en códices y en documentos. Un concepto éste que en nada tiene que ver con el de inscripción que, como hemos señalado, no debe ligarse ni al soporte ni al modo de escribir, o al uso de una escritura llamativa, sino que la definición de inscripción debe definirse e partir de la función eminentemente publicitaria de estos textos, "escrito en orden a una publicidad universal y perdurable"29.

No cabe duda de que un epígrafe no es otra cosa que un acto de publicidad, y así vemos, por ejemplo, que desde época clásica las leyes "se mandaban grabar para que pudieran ser leídas fácilmente y llegaran al conocimiento público”30. Pero además, sus caracteres hacen que esta publicidad resulte, para la mayoría de

\footnotetext{
${ }^{25}$ Ch. LAMBERT, Pagine di pietra. Manuale di epigrafia latino-campana tardoantica $e$ medievale, Salerno, 2004, p. 13.

${ }^{26}$ W. KOCH, Inschriftenpaläographie des abendländischen Mittelalters und der früheren Neuzeit, Munich, 2007, p. 23.

${ }^{27}$ W, KOCH, Inschriftenpaläographie... p. 25.

${ }^{28}$ V. GARCÍA LOBO, La escritura publicitaria en la Península ...

${ }^{29}$ V. GARCÍA LOBO, Los medios, p. 17.

${ }^{30}$ Lex Irnitana, 95 y G. ALFÖLDY, Corpus Inscriptionum latinarum. Conventus Antigitanus, Berlín, 1998, p. 289.
} 


\section{NATALIA RODRÍGUEZ SUÁREZ \\ UN REPASO A TRAVÉS DE LOS CONCEPTOS DE EPIGRAFÍA E INSCRIPCIÓN}

los casos, perdurable en el tiempo. Como decía Plinio el joven no había mejor manera de publicitar un mensaje que mediante la inscripción y que, por tanto, "la incisión del nombre personal sobre un monumento fuera entendida en la

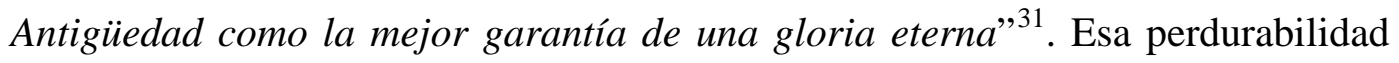
hace, además, que resulte universal, porque nos alcanza incluso a nosotros hoy.

Lo que diferencia y distingue al epígrafe es su valor publicitario, esto es lo que le da carta de naturaleza a la inscripción. Ligado a ésta aparecen otros dos conceptos: el de perdurabilidad y el de universalidad. Estos aspectos, que parecen evidentes en líneas generales, se ven necesariamente matizados al observar ciertos ejemplos.

Respecto al primero de los conceptos, la perdurabilidad, podemos traer a colación las condiciones para pintar y dorar el túmulo para las honras a la reina en el Convento de Santo Domingo el Real en Madrid: “... en el banco último, que recive la media naranja, se an de hacer quatro cartelones en que se an de escrebir quatro descripciones que se les dará por memoria”32. En ellas se alude a que el túmulo había de llevar cuatro inscripciones. No hay duda de que lo que recogían esos carteles, a los que se alude, eran epígrafes, ciertos mensajes que se querían publicitar. Pero la perdurabilidad de éstos era relativa, pues, estos túmulos, construidos para las honras a la reina, tenían una vida limitada, servían y se construían para ese acontecimiento y después eran desmontados y destruidos, puesto que ya habían cumplido con su función ${ }^{33}$.

Otro tipo de ejemplo serían los mensajes que presentan las lipsanotecas, en las que se colocaba leyendas alusivas a las reliquias que contenía u otros textos como Dedicationes o Consecrationes $^{34}$. El mensaje quedaba a la vista de los fieles durante la ceremonia de consagración, y después desaparecía dentro del altar. ¿Qué sucede con las inscripciones de las ostias sagradas? El profesor Favreau señalaba que los mensajes que se incluían en este pan sagrado no eran otra cosa

\footnotetext{
${ }^{31}$ PLINIO EL JOVEN, Panegírico al emperador trajano, 54, p. 7, J. ANDREU PINTADO (Coord), Fundamentos de epigrafía Latina, Navarra, 2009, p. 3.

${ }^{32}$ M. AGULLÓ Y COBO, Documentos para la historia de la escultura española, Madrid, 2005, p. 380.

${ }^{33}$ E. RUIZ GARCÍA, “Aspectos representativos en el ceremonial de unas reliquias reales (a. 1504-1516)” La España medieval, n 26, 2003, pp. 263-294.

${ }^{34}$ M. J. BARROCA y M. L. REAL, "Caixas-Relicário medievais do misterio de S. Torcato (Guimar̃es)”, Arqueologia Medieval, vol. 1, Oporto-Mértola, 1992, pp. 135-168. J. DE SANTIAGO FERNÁNDEZ, "Inscripciones en lipsanotecas y tapas de altar catalanas de los siglos X-XII. Su origen y función”: Signo Revista de Historia de la Cultura Escrita, n. 10, 2002, pp. 3562. C. TREFFORT, Mémoires carolingiennes. L'épitaphe entre célébration mémorielle, genre littéraire et manifeste politique (milieu VIII ${ }^{e}$-début XI ${ }^{e}$ siècle), Rennes, 2007, pp. 44-57.
} 
que inscripciones, que publicitaban que ese pan era el cuerpo de Cristo $^{35}$. Sin embargo, de nuevo la perduración en el tiempo de dicha inscripción es relativa, al igual que lo es la universalidad de la misma, como demuestran los ejemplos.

La universalidad de la inscripción también es parcial. Efectivamente si nos alcanza a nosotros, que podemos acceder hoy a los textos, la universalidad del destinatario parece clara. Sin embargo, en origen, muchas de esas inscripciones fueron concebidas para ser leídas por un grupo muy reducido. Piénsese en el caso, siempre recurrido, de los claustros de ciertos monasterios medievales, cuyo acceso era muy restringido. El doctor Debiais ya señala que " $L$ 'universalité de la publicité épigraphique est donc réduite par les conditions matérielles de la mise en place des inscriptions. Dans certains cas, elle est consciemment entravée pour entraîner une sélection du public : l'inscription perd alors son caractère publicitaire universel" ${ }^{36}$.

Es cierto que hoy podemos leer esas inscripciones, pero ¿qué pasa, por ejemplo, con las que se perdieron bajo capas de cal? Si no nacieron con una idea de universalidad y tampoco la han alcanzado porque se perdieron en el camino ¿dejarían de ser inscripciones? Cualquier especialista respondería inmediatamente que no, que por supuesto esos mensajes que nacieron con un fin publicitario eran y seguirán siendo inscripciones.

Por todo ello, pensamos que quizás convendría matizar los conceptos de universal y perdurable, ligándolos a la función para la que nació la inscripción. De modo que, las inscripciones que se realizaron en las arquitecturas efímeras, nacieron con el fin de que todos los asistentes al acto pudieran contemplar el texto. Así, en su contexto el mensaje es universal y éste perduraba hasta que la inscripción perdía la función para la que fue creada. Sucede de la misma manera en el caso de las lipsanotecas o de las ostias sagradas.

Así pues, los ejemplos expuestos muestran que la universalidad y la permanencia son valores relativos, circunscritos y aplicables al uso que el autor pretendía darle a la inscripción, y en función de esos deseos cumplirá con esa universalidad y perdurabilidad más o menos limitadas. De modo que, podríamos concluir diciendo que la inscripción es el mensaje escrito en orden a una publicidad universal y perdurable de acuerdo a la función para la que nació el epígrafe.

${ }^{35}$ R. FAVREAU, “L'épigraphie comme source poru la liturgie”: Vom Quellenwert der Inschriften. Vorträge und Berichte der Fachtagung Esslingen 1990, Heidelberg, 1992, p. 99.

${ }^{36}$ V. DEBIAIS. Messages de Pierre. La lecture des inscriptions Dans la communications médiévale (XIII ${ }^{e}-X I V^{e}$ siècle), Turnhout, 2009, p. 248. 